\title{
TRAÇO DE UNIÃO ENTRE FIXISMO E MOBILISMO
}

B.B. de Brito Neves ${ }^{1}$

A Geotectônica nasceu, tem vivido e tem sido revivificada, sob o signo do debate científico. Como o ramo mais abrangente das ciências geológicas, ela é ao mesmo tempo de grande carência de fatos científicos, de forma que nenhuma informação geológica nova é dispensável ao seu contexto.

Assim sendo, é a facção das geociências mais sensível ao progresso do conhecimento, nas muitas variáveis envolvidas neste progresso, nas diferentes escalas de espaço (geográfico/geológico) e tempo. Tendo ainda em vista a diversidade dos centros de investigação científica (geográfica, formação, afinidade, idioma, natureza dos paradigmas), facilmente se entende a pluralidade de hipóteses, teorias e modelos. Nestes termos, o debate é conseqüência natural, pois o "nosso modelo" é sempre melhor do que "o do nosso vizinho" e "sempre será melhor daquele do nosso rival político ou científico", como ilação livre de um pensamento einsteiniano.

Neste século, a partir dos anos 60 , o debate fixismo $\mathrm{x}$ mobilismo recrudesceu e esteve em destaque, não deixando nenhum geocientista indiferente.

Fixismo - cunho pejorativo e irônico criado pela outra facção - e fixistas de um lado, seguidores da Teoria Geossinclinal, ou da chamada Escola Kober-Stille-Aubouin. Na realidade, escola que primou pela descrição detalhada (que? onde? como?), a comparação com os paradigmas (Alpes, Apalaches), muito afeita às ciências naturais, e que sempre deixou as causas (por que?) em plano secundário (Teoria da contração ou outras de fundamentação discutível) em seus modelos. Esta escola subsidiou de forma notável o desenvolvimento das ciências geológicas por mais de um século.

Mobilismo e mobilistas estariam agora atrelados à chamada "Tectônica de

\footnotetext{
${ }^{1}$ Departamento de Geologia Geral, Instituto de Geociências/USP, São Paulo.
} 
Placas", nascida no fato do "sea floor spreading", com Hess, Tuzo Wilson, Le Pichon, Parker, e muitos outros, a partir da avalanche de descobertas geológicas/geofísicas de 1960 em diante. Por convicção, corrente afeita às ciências exatas e aos dados físicos e químicos da Terra e do seu interior.

Durante vinte anos, com respingos até o presente, mobilistas e fixistas tem-se digladiado de várias formas, em vários fronts: artigos, réplicas, simpósios, congressos, a boca pequena. Um abismo foi gradativamente sendo criado entre estas facções. Se já preexistia prolixa terminologia geossinclinal, nova terminologia mobilista começou a vicejar. Raramente houve a preocupação de ligar termos novos com termos preexistentes, de forma que por muito tempo estas linguagens estarão em searas paralelas.

Em 1977, A. Kroner advertiu sobre a necessidade imperiosa de um traço de união entre as duas facções, e o C.G.I. de Paris, 1980, colocou-as lado a lado nas mesmas salas para aparar arestas (com poucos resultados práticos).

Sem dúvida, a Teoria Geossinclinal e seus modelos pertencem ao passado. Mas é necessário reconhecer e mostrar a riqueza de sua terminologia "naturalista" e "descritivista", posto que de forma sobranceira ela preconizou e designou todos os processos e acidentes geológicos/geotectônicos que hoje estão sendo "redescobertos" e interpretados à luz da tectônica global.

É preciso enaltecer a antecipação dos fixistas, mais afeitos à descrição (duas dimensões), menos preocupados com causas, eles foram extremamente felizes no seu amplo leque de observações e designações. Em várias áreas pré-cambrianas do mundo - inclusive no Brasil - foi com o poder de discernimento e a terminologia fixista que se alicerçaram as bases de toda regionalização geotectônica já feita e a ser feita. Isto em condições "sine qua non", ou seja sem esta terminologia muito pouco teria sido feito até agora. Mesmo porque ainda nos faltam os dados da $3^{\mathrm{a}}$ dimensão (e dos outros compromissos) da Tectônica Global.

Para conferir esta verdade, é só rever ALMEIDA (1967) e ALMEIDA (1969), quando as estacas do nosso conhecimento geotectônico foram afincadas.

Muita gente não se refere a isto por puro desconhecimento da história, ou ainda por puro arrivismo, com relação às ordens e às falas da matriz cultural.

A coleção de termos aqui posta foi escolhida baseada nos clássicos da análise geotectônica do Brasil e de suas sínteses (vide ALMEIDA \& HASUI, 1984 e SCHOBBENHAUS et al., 1984) principais. É uma amostragem pequena, mas suficiente e representativa para clarear o abismo que tem assustado e agitado os incautos (além de BATES \& JACKSON, 1980). 
O interessante é notar que praticamente todos os termos da tectônica global, velhos, novos, novíssimos (em fase de introdução) já dispunham de equivalentes, de cunho absolutamente naturalista, desvinculados de certa forma das razões de causa. E este compromisso de causa (por que?), louvável, dos mobilistas, está fazendo nascer e crescer vertiginosamente nova terminologia na Geotectônica.

De fato, de fato mesmo, o abismo é de linguagem. Não há qualitativamente muito de novo debaixo do Sol (parafraseando-se o Livro do Eclesiastes). Isto não significa que não esteja havendo progresso, tendo em vista a modernização dos modelos e a possibilidade de quantificaçăo dos fenômenos tectônicos, e sobretudo a identificação concreta das causas (efeitos) dos movimentos tectônicos.

\section{REFERÊNCIAS BIBLIOGRÁFICAS}

ALMEIDA, F.F.M. de (1967) Origem e Evolução da Plataforma Brasileira. Boletim DGM/DNPM, (241):1-36.

ALMEIDA, F.F.M. de (1969) Diferenciação Tectônica da Plataforma Brasileira. In: CONGRESSO BRASILEIRO DE GEOLOGIA, 23, Salvador, 1969. Anais. Salvador, SBG, p.29-46.

ALMEIDA, F.F.M. de \& HASUI, Y. (1984) O pré-Cambriano do Brasil. São Paulo, Edgard Blücher, 378p.

BATES, R.L. \& JACKSON, J.A (1980) Glossary of Geology. 2.ed. Falls Church, American Geological Institute. 751p.

HOFFMAN, P.F. (1989) Precambrian geology and tectonic history of North America. In: BALLY, A.W. \& PALMER, A.R. (eds.) The geology of North America: an overview. Boulder, Colorado, G.S.A. p.447-512.

KRÖNER, A. (1977) The Precambrian geotectonic evolution of Africa: plate accretion versus plate destruction. Precambrian Research, 4(2):163-213. 
KRÖNER, A. (1987) Proterozoic lithospheric evolution. Boulder, American Geophysical Union. 273p. (Geodynamics Series, 17).

SCHOBBENHAUS, C.; CAMPOS, D.A.; DERZE, G.R.; ASMUS, H.E. (1984) Geologia do Brasil: texto explicativo do mapa geológico do Brasil e da área oceânica adjacente, incluindo depósitos minerais, Escala 1:2.500.000. Brasília, MME/DNPM. 501p.

WINDLEY, B.F. (1984) The evolving continents. 2.ed. Chichester, John Wiley. 399p. 


\section{ENSAIO DE EQUIPARAÇÃO DOS TERMOS MAIS USUAIS}

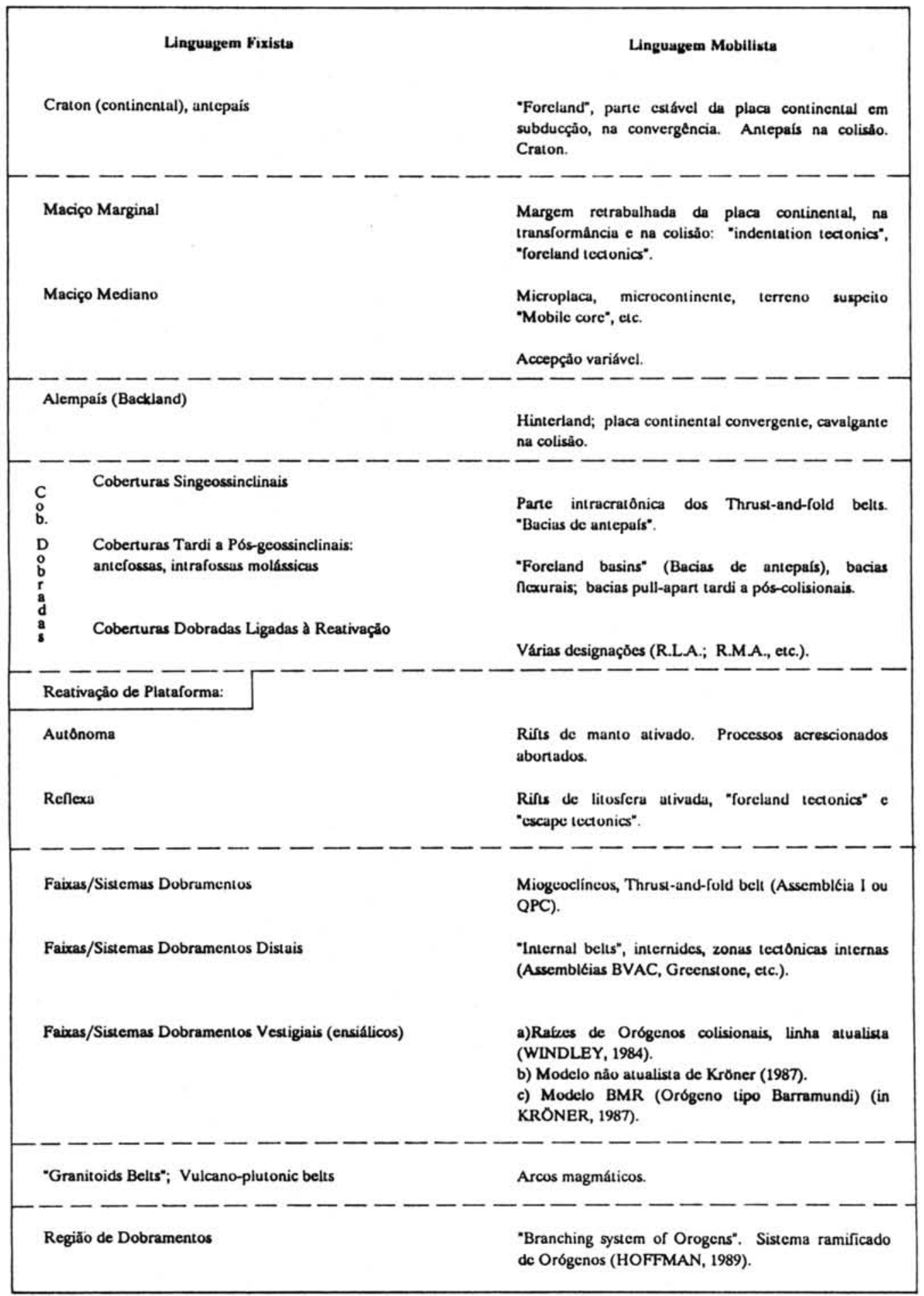

